\title{
From art to science: the functional damage due to thumb osteoarthritis finely described by Velazquez 300 years before its clinical description
}

\author{
J.H. Villafañe ${ }^{1}$, R. Cantero-Tellez ${ }^{2}$, S. Negrini ${ }^{1,3}$, P. Berjano ${ }^{4}$ \\ IIRCCS Fondazione Don Carlo Gnocchi, Milan, Italy; ${ }^{2}$ Tecan Hand Center, Malaga, Spain; \\ ${ }^{3}$ University of Brescia, Brescia, Italy; 4IRCCS Istituto Ortopedico Galeazzi, Milan, Italy
}

\begin{abstract}
SUMMARY
Velazquez showed to know the entity of thumb osteoarthritis by finely describing it in one of his paintings. The concepts of anatomical damage, loss of strenght, and functional impairment are transmitted to the observer.
\end{abstract}

Key words: Thumb, Carpometacarpal, Osteoarthritis.

Reumatismo, 2017; 69 (3): 137-139

\footnotetext{
T
}

he thumb requires a breadth of motion to perform tasks that are uniquely human, from forceful grasp to fine pinch. The first carpometacarpal (CMC) joint plays a major role in this function. The evolutionary demands for prehension and manipulative activity have been described as a major driver of the hominid species' upright standing, freeing the torso and upper limbs (1). First CMC osteoarthritis (OA) is a degenerative alteration of the $\mathrm{CMC}$ joint that is characterized by abrasion, progressive deterioration of the joint surfaces, ligamentous laxity, and osteophyte formation at the site of damage (2). OA of the first CMC joint affects $15 \%$ of adults older than 30 years and $66 \%$ of women older than 55 years (3). The resultant loss of thumb function may result in a $40 \%$ to $50 \%$ impairment of the upper extremity (3).

The thumb CMC OA was first described from a medical point of view by Jacques Forestier in 1937 (4). Although no radiograph appears in his three-page communication (5), Paul Robert explained the anatomy of the trapezium in 1936 (6). He provided an apt description of how the radiographic view assists in diagnosing first CMC arthritis progression. He commented on a continuum from subchondral sclerosis, osteophyte formation, to joint degradation (6).

Although nowadays different methods are useful for the diagnosis of the first CMC joint, such as conventional radiology or magnetic resonance imaging (MRI), biomechanical studies on this articulation have shown that forces increase exponentially (up to $1200 \%$ ) from the tip of the thumb to the CMC joint with grasp and forceful pinch with compressive forces causing pain and functional impotence in daily activities (7-9). Pain at the base of the thumb during everyday activities can cause substantial impairment in hand function. Currently, education, topical NSAID, thumb orthoses, thumb exercise, surgical treatment after medical and injective therapy are used to diminish pain and subsequently increase the functional pinch strength of patients with first CMC joint OA.

Although the disease was described for the first time by Forestier in 1937, previous illustrations highlighted first CMC joint deformity but also thumb dysfunction through art. The interpretation of the visual arts can be an important tool for paleopathological research of some rheumatic diseases before $\overline{\text { Corresponding author }}$ Jorge Hugo Villafañe Regione Generala 11/16 10045 Piossasco (TO), Italy E-mail: mail@villafane.it 


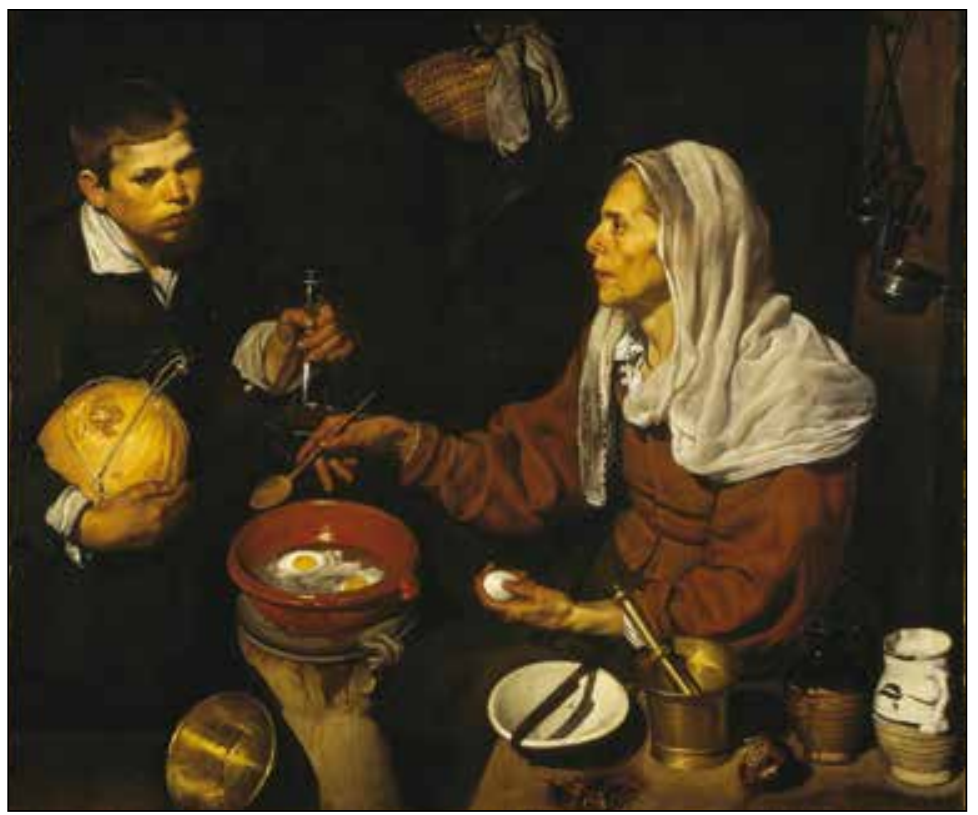

Figure 1 - Old Woman Frying Eggs, Diego Velázquez, 1618. Reproduced with permission of the National Gallery of Scotland in Edinburgh.
1623. Velázquez worked particularly hard on the detail of the figures' hands (12). In fact, the painting illustrates the functional deformity of the first CMC joint of the old woman's left and right hands, with surprising anatomical accuracy for a disease that had not yet been described from the medical point of view. The elderly woman's left thumb metacarpal base subluxates dorso-radially due to ligament laxity (13). On her right hand, the metacarpal shaft flexes and adducts secondary to tethering to the index finger metacarpal by the adductor pollicis. Over time, this results in a first web space contracture. To allow pinch, the metacarpophalangeal (MP) joint compensates with hyperextension, which results in a zigzag- or Z-deformity, Figure 1 (14).

Through the painting, Velázquez not only describes the thumb deformity that years later would be recognized as the first CMC joint OA, but he also emphasizes the loss of manual function and the lateral pinch in the right hand as a prelude to postural ergonomics to reduce pain during activities of daily living.

Whether or not the artist was cognizant of the disease, he visually described the anatomical deformity, loss of strength, and functional re-education through his painting.

Author contributions: JHV, design of the study and interpretation of the results, writing, submission and tracking of manuscript; RC, interpretation of the results, writing, submission and tracking of manuscript; PB, SN, writing, submission and tracking of manuscript.

Conflict of interest: the authors declare no conflict of interest.

\section{REFERENCES}

1. Ladd AL. Upper-limb evolution and development: skeletons in the closet. Congenital anomalies and evolution's template. J Bone Joint Surg Am. 2009; 91: 19-25.

2. Bertozzi L, Valdes K, Vanti C, Negrini S, Pillastrini P, Villafane $\mathrm{JH}$. Investigation of the effect of conservative interventions in thumb 
carpometacarpal osteoarthritis: systematic review and meta-analysis. Disabil Rehabil. 2015; 37: 2025-43.

3. Villafane $\mathrm{JH}$, Valdes K, Berjano P, Wajon A. Clinical update: conservative management of carpometacarpal joint osteoarthritis. J Rheumatol. 2015; 42: 1728-9.

4. Internullo G. [Trapeziometacarpal joint osteoarthritis: treatment with tendon interposition arthroplasty according to Ceruso in severe osteoarthritis]. Reumatismo. 2008; 60: 125-30.

5. Ladd AL. Editorial comment: symposium: thumb carpometacarpal arthritis. Clin Orthop Relat Res. 2014; 472: 1093-4.

6. Robert M. The classic: radiography of the trapeziometacarpal joint. Degenerative changes of this joint. 1936. Clin Orthop Relat Res. 2014; 472: 1095-6.

7. Kroon FP, Conaghan PG, Foltz V, et al. Development and Reliability of the OMERACT Thumb Base Osteoarthritis Magnetic Resonance Imaging Scoring System. J Rheumatol. 2017 [Epub ahead of print].

8. Ramonda R, Favero M, Vio S, et al. A recently developed MRI scoring system for hand osteoarthritis: its application in a clinical setting. Clin Rheumatol. 2016; 35: 2079-86.

9. Cooney WP, 3rd, Lucca MJ, Chao EY, Linscheid RL. The kinesiology of the thumb trapeziometacarpal joint. J Bone Joint Surg Am. 1981; 63: 1371-81.

10. Hinojosa-Azaola A, Alcocer-Varela J. Art and rheumatology: the artist and the rheumatologist's perspective. Rheumatology (Oxford). 2014; 53: 1725-31.

11. Dequeker J. What can a rheumatologist learn from paintings? Acta Reumatol Port. 2006; 31: 11-3.

12. Old Woman Frying Eggs 2010 [updated August 2010; cited 2017 March 04]. Available from: https://en.wikipedia.org/wiki/Old_Woman_ Frying_Eggs

13. Castillo-Ojugas A. Trapeziometacarpal osteoarthrosis in a painting by Diego Velazquez. Arthritis Rheum. 1991; 34: 127-8.

14. Brogan DM, Kakar S. Metacarpophalangeal joint hyperextension and the treatment of thumb basilar joint arthritis. J Hand Surg Am. 2012; 37: 837-8. 